\title{
EVOLUÇÃO DA IMUNIDADE PASSIVA EM FÊMEAS BOVINAS DA RAÇA HOLANDESA ${ }^{1}$
}

\author{
EVOLUTION OF PASSIVE IMMUNITY IN HOLSTEIN HEIFERS
}

\author{
Mauro Pires Moraes $^{2}$ Rudi Weiblen ${ }^{3}$ Adriana Moraes da Silva ${ }^{4}$ \\ Fernando Luiz Tobias ${ }^{5}$
}

\section{RESUMO}

Determinou-se a quantidade de imunoglobulinas (lgs) séricas em 1.530 amostras coletadas de 81 vacas, no periodo de 28 dias pré e pós-parto $(n=579)$, e suas terneiras, no periodo até 210 dias $(n=951)$ pela técnica de turvação pelo sulfato de zinco. Os niveis de imunoglobulinas das vacas demonstraram queda nas duas semanas pré-parto, indicando uma transferência de Igs da corrente circulatória para a glândula mamária. A média de imunoglobulinas séricas às 24 horas de vida em 76 terneiras foi de $11,66 \mathrm{mg} / \mathrm{ml}$ (desvio padrão de 7,4). Foram considerados como animais com falha da transferência da imunidade passiva (FPT) aqueles que apresentaram niveis inferiores a um desvio padrão abaixo da média $(4,2 \mathrm{mg} / \mathrm{ml})$. Os animais com FPT demonstraram diferença no comportamento da evolução das imunoglobulinas séricas até os 56 dias de idade comparado com os demais. Ao comparar-se diferentes métodos de quantificação de imunoglobulinas observou-se alta $(r=0,91)$ associação entre a técnica de turvação e eletroforese associada às proteinas totais séricas $e$ baixa eficiência das técnicas de precipitação por sulfito de sódio e coagulação por glutaraldeido.

Palavras-chave: imunidade passiva, bovino, imunoglobulinas

\section{SUMMARY}

The zinc sulfate turbidity test (ZST) was used to determine the immunoglobulin concentration in 1.530 serum samples collected from 81 cows ( 28 days before parturition to 28 days after parturition $-n=579$ ). Heifers born from these cows were also tested until 210 days of live ( $n=951$ ) with the same test. Levels of Igs in cows decreased during the two weeks prepartum, indicating a transfer of circulating Igs to the mammary gland. The average serum Igs at 24 hours after birth in 76 female calves was $11.66 \mathrm{mg} / \mathrm{ml}$ with a standart deviation (SD) of 7.4. Failure of passive transfer (FPT) was considered to occur in animals with levels of Igs lower than one $S D$ below average $(4.2 \mathrm{mg} / \mathrm{ml}) . F P T$ animals had lower levels of serum Igs than the other group until 56 days of age. High correlation ( $r=0.91)$ between ZST and serum electrophoresis was observed. Sodium sulfite precipitation and glutaraldehyde coagulation tests were less efficient than ZST.

Key words: passive immunity, bovine, imunoglobulins.

\section{INTRODUÇÃO}

A imunidade passiva é adquirida a partir do colostro materno, um concentrado de imunoglobulinas, que é formado a partir de níveis séricos e passado da fêmea ao terneiro durante as primeiras horas de vida. O colostro é formado pela passagem de imunoglobulinas séricas para a glândula mamária, as quais chegam a um valor máximo no momento do parto (SASAKI et al., 1976).

Muitas pesquisas vêm sendo realizadas sobre os fatores que interferem com a transferência da imunidade passiva (REBELATTO \& WEIBLEN,

\footnotetext{
- ${ }^{1}$ Parte da dissertação de Mestrado apresentada pelo primeiro autor ao Curso de Pós-graduação em Medicina Veterinária, Universidade Federal de Santa Maria (UFSM). Projeto parcialmente financiado pelo CNPq e FAPERGS.

${ }^{2}$ Médico Veterinário, Pós-graduando em Medicina Veterinária.

${ }^{3}$ Médico Veterinário, Professor Titular, MSc, PhD, Departamento de Medicina Veterinária Preventiva, UFSM, 971 19-900, Santa Maria, RS, Brasil. E-mail: rudi@creta.ccr.ufsm.br. Autor para correspondência.

${ }^{4}$ Médico Veterinário, bolsita de aperfeiçoamento do CNPq.

${ }^{5}$ Bolsista de Iniciação Científica do CNPq. 
1992). Estes fatores podem ser ambientais (ROY, 1990; STOTT et al., 1976), ligados diretamente à condição do terneiro (BESSER et al., 1990), ou ligados à fêmea (BRANDOM et al., 1971; SASAKI $\boldsymbol{e t}$ al., 1976; WINGER et al., 1995).

O envolvimento de vários fatores podem levar à falha na transferência da imunidade passiva (FPT) (HANCOCK, 1985). Seu diagnóstico e as consequiências provocadas por esta situação não são bem claras, pois os valores definidos para o diagnóstico podem levar a decisões incorretas (GARRY et al., 1993). Segundo PERINO et al. (1993), o meio mais exato para verificar a FPT é a quantificação de imunoglobulinas séricas em animais nos primeiros dias de vida. A FTP é um sério e atual problema em terneiros, e apesar da demonstração de vários fatores que interferem nesse processo, ainda é um obstáculo na produtividade.

Um método direto de quantificação de imunoglobulinas é a eletroforese (PFEIFFER $\boldsymbol{e t}$ al., 1977). Esta técnica, apesar de ser bastante específica, exige boa condição técnica e necessita de equipamentos específicos. O método da turvação pelo sulfato de zinco (TSZ), apesar de ser um método indireto e menos específico que os métodos diretos é uma prova rápida, com baixo custo (WHITE, 1986) e simples (McEWANN, 1970). Além disso, PFEIFFER et al. (1977) demonstraram que este método foi o que apresentou menos distorções em relação a quantidade real de imunoglobulinas em amostras de soro bovino, comparado com imunodifusão radial simples, eletroforese e refratometria. Outros métodos indiretos de quantificação de imunoglobulinas são a precipitação pelo sulfito de sódio (PFEIFFER \& McGUIRE, 1977) e a reação de coagulação pelo glutaraldeído (TENNANT et al., 1979).

Este trabalho teve como objetivo avaliar a evolução dos níveis de imunoglobulinas (Igs) séricas de vacas prenhes no período de 28 dias antes e após o parto, assim como de suas terneiras até os 210 dias de idade. Nas terneiras, quantificou-se a transferência da imunidade passiva. Ainda, objetivou-se comparar e avaliar quatro métodos de mensuração de imunoglobulinas séricas.

\section{MATERIAIS E MÉTODOS}

Foram utilizadas 81 fêmeas bovinas da raça Holandesa e respectivas filhas oriundas de uma propriedade produtora de leite tipo B, localizada na região central do Estado do Rio Grande do Sul. Apenas crias fêmeas foram utilizadas, pois os machos eram descartados logo após o nascimento. As parições ocorreram no período de março a junho de 1994. As terneiras foram retiradas de suas mães logo após o nascimento e colocadas em terneireiras individuais. A seguir, fornecia-se um "pool" colostral nos dois primeiros dias objetivando um aporte de imunoglobulinas às crias. Posteriormente, os animais recebiam leite in natura e, gradativamente, o concentrado e o feno. O desmame das terneiras foi realizado aproximadamente aos dois meses de idade, após o qual os animais foram mantidos em pequenos piquetes.

Foram testadas 1.530 amostras de soro, sendo destas 579 de 81 vacas e 951 de suas crias. Nas vacas as amostras foram coletadas $28,21,14,7$ e 1 dias antes do parto e no dia 1, 7, 14, 21 e 28 após o parto. Nas temeiras, as amostras foram coletadas ao nascimento às 6,12 e 24 horas de vida e aos $7,14,21$, $28,35,42,49,56,63,90,120,150,180$ e 210 dias de idade.

A técnica de turvação por sulfato de zinco foi realizada conforme descrito por PFEIFFER et al. (1977) com algumas modificações. A leitura da turbidez foi realizada (em absorvância) em espectrofotômetro a a $485 \mathrm{~nm}$. Através da turbidez, estimou-se a quantidade de imunoglobulina em miligramas por mililitro $(\mathrm{mg} / \mathrm{ml})$ utilizando uma curva padrão delineada com soro bovino fetal (SBF) com quantidades conhecidas de $\gamma$-globulina bovina. Para a elaboração da curva, realizaram-se quatro repetições para cada ponto e cada repetição foi submetida a quatro leituras em diferentes ocasiões. Os pontos foram distribuídos nas concentrações de $0,5,15,25$ e $35 \mathrm{mg} / \mathrm{ml}$. O efeito da hemólise sobre a turbidez foi determinada conforme descrito por PFEIFFER et al. (1977).

A eletroforese foi realizada conforme descrito por PFEIFFER et al. (1977). O percentual de cada fração protéica foi medido por leitura em densitômetro $^{b}$ e a concentração de $\gamma$-globulina e demais proteínas foi calculada como o produto da concentração de proteínas totais pelo percentual da fração. A proteína sérica total foi determinada através de um "kit" comercial ${ }^{c}$ pelo método colorimétrico com leitura em espectofotômetro. O método de precipitação por sulfito de sódio foi executada conforme descrito por PFEIFFER \& McGUIRE (1977). O teste de coagulação por glutaraldeído foi realizada como descrito por TENNANT et al. (1979).

A técnica de turvação por sulfato de zinco foi comparada com a técnica de eletroforese associada às proteínas totais pelo método de regressão. Ao comparar estas técnicas, foram utilizadas apenas as amostras que não apresentavam nível de hemólise maior que $1 \%$ e quantidades maiores que $40 \mathrm{mg} / \mathrm{ml}$ de imunoglobulinas séricas. A avaliação das técnicas 
qualitativas (técnicas de precipitação por sulfito de sódio e coagulação por glutaraldeído) foi realizada pela comparação com a quantidade de $\gamma$-globulina determinada pela técnica de turvação por sulfato de zinco.

Os animais foram considerados com falha da transferência da imunidade passiva (FPT) quando apresentavam niveis séricos de imunoglobulinas, determinados pela prova de turvação pelo sulfato de zinco, inferiores a um desvio padrão abaixo da média mensurada às 24 horas de idade.

Para determinar as curvas de comportamento das imunoglobulinas e comparar as técnicas quantitativas, utilizou-se análise de regressão com diferentes modelos selecionando-os através dos seus coeficientes de regressão (R2) associado ao teste $\mathrm{F}$. O teste $\mathrm{X}^{2}$ foi utilizado ao comparar técnicas qualitativas. Os testes foram aplicados conforme descrito por STEEL \& TORRIE (1980).

\section{RESULTADOS E DISCUSSÃO}

O nivel médio de imunoglobulinas séricas detectadas nas amostras de 76 terneiras com 24 horas de idade, pela técnica de sulfato de zinco, foi de $11,66 \mathrm{mg} / \mathrm{ml}$, com desvio padrão de 7,4 . Amplas variações nas concentrações de imunoglobulinas séricas encontradas em recém-nascidos são descritas por outros pesquisadores (PERINO et al., 1995, TOOD \& WHITE, 1995, WITTUM \& PERINO, 1995). Apesar da variação observada entre os animais, o nível médio de Igs séricas da população pode ser um indicativo de suas condições quanto ao aporte de imunidade passiva.

O tempo de fornecimento do colostro após o nascimento de terneiros da raça holandesa foi estudado por TOOD \& WHYTE (1995). Esses autores demonstraram que os grupos de animais que receberam colostro uma só vez em períodos determinados, que variavam de 2 a 8 horas de idade, não possuíam diferenças nas concentrações médias entre os grupos e foram semelhantes aos resultados na presente pesquisa. DONOVAN et al. (1986), ao analisarem 2.103 temeiros nascidos na Flórida no período de dois anos, observaram os efeitos sasonais na absorção de colostro. Essas diferenças podem ser esclarecidas pelas obsèrvaçôes de STOTT et al. (1976) que demonstraram influência direta da temperatura corporal e ambiental na absorção de imunoglobulinas.

A grande variabilidade nas concentrações de Igs séricas, encontrada nos trabalhos relativos à transferência da imunidade passiva e decorrentes da influência de fatores externos (REBELATTO \&
WEIBLEN, 1992), dificulta a determinação do que se chama de falha da transferência da imunidade passiva (FPT). As quantidades mínimas de imunoglobulinas séricas que devem ser obtidas passivamente nas primeiras horas de vida de terneiros variam entre os autores (HANCOCK, 1985; ROBISON et al., 1988; WITTUM \& PERINO, 1995). O critério adotado nesta pesquisa foi o mesmo utilizado por McGUIRE et al. (1976) que se baseia na média e desvio padrão da quantidade de imunoglobulinas séricas das amostras. A opção por esse parâmetro justifica-se, principalmente, por tratar-se de uma referência regionalizada desses dados. GARRY et al. (1993) afirmam que valores específicos para definir o diagnóstico de FPT podem levar a suposições incorretas. Esses autores acreditam que o conceito de falha na transferência da imunidade passiva não deve ter aplicação absoluta, pois trata-se de uma equação complexa na qual a concentração de imunoglobulinas é somente um fator.

Baseados no nível médio de $\gamma$-globulina e desvio padrão, os animais foram divididos em dois grupos de animais: normal - aqueles que apresentaram nível de Igs maior que $4,2 \mathrm{mg} / \mathrm{ml}$ (referente a um desvio padrão abaixo da média) e com falha na transferência da imunidade passiva (FPT) - aqueles que apresentaram nível de Igs menor que $4,2 \mathrm{mg} / \mathrm{ml}$. A proporção de animais que apresentaram falha da transferência da imunidade passiva (FPT) foi menor quando comparada com outros relatos (ROBISON et al., 1988, WITTUM \& PERINO, 1995), mas os dados de 14,5\% (11/76) foram semelhantes com aqueles apresentados por McGUIRE et al.(1976) e PERINO et al. (1995). Acredita-se que estas comparações são muito limitadas, devido aos diferentes desenhos experimentais analisados. Além disso, HANCOCK (1985) estudando 19 rebanhos relatou uma grande variação na taxa de animais com baixa imunidade passiva. A mesma situação foi encontrada por WHITE \& ANDREWS (1986), ao analisarem trabalhos realizados por pesquisadores no Reino Unido e Estados Unidos.

A evolução dos niveis de Igs séricas em 887 amostras coletadas de 76 terneiras do nascimento até 120 dias de idade (Figura 1) demonstra um comportamento diferente entre os animais que sofreram FPT $(n=11)$ e os que tiveram uma transferência normal de imunidade passiva $(n=65)$. Os animais com FPT apresentaram quantidades significativamente menores de imunoglobulinas $(\mathrm{P}<0,01)$ até os 56 dias de idade. Após esta data, embora o gráfico apresente diferenças visuais, estas não foram significativas. LAMOTE (1977) demonstraram que a produção endógena de imunoglobulinas inicia-se mais cedo em animais que 
não consomem colostro. RAJALA \& CASTRÉN (1995) notaram um aumento da imunoglubulina $M$ $(\operatorname{IgM})$ e $\mathrm{A}(\operatorname{IgA})$ a partir da quarta semana de idade. $\mathrm{O}$ aumento na produção destes dois tipos de Igs não refletiu em aumento na imunoglobulina total de animais que apresentavam altos níveis de Igs após o nascimento. Em animais com baixos níveis de Igs séricas, no entanto, esse aumento foi observado. Notase na Figura 10 incremento no aumento da Ig séricas a partir do $28^{\circ}$ dia aproximando os pontos observados da linha da regressão. Ao observar os níveis de imunoglobulinas nos dois grupos nos primeiros 7 dias observa-se que o grupo de animais com FPT não sofreu queda nos níveis de imunoglobulinas no primeiro até o sétimo dia, enquanto no grupo normal a queda é evidente. Esse fato justificar-se-ia ao ser considerada a existência de diferentes taxas de decréscimo nos níveis de Igs séricas de animais com quantidades elevadas ou baixas de Igs séricas, como descrito por LAMOTE (1977).

Também foi observada a evolução da quantidade de $\gamma$-globulinas mensuradas através da técnica de turvação pelo sulfato de zinco em 579 amostras de soro de 81 fêmeas bovinas da raça holandesa no periodo de 28 dias pré-parto até 28 dias pósparto. Através da análise de regressão, observa-se uma queda nos níveis séricos de Igs no período entre 14 dias antes do parto até 7 dias pós-parto (Figura 2). A diminuição da quantidade de imunoglobulinas pode ser explicada pela transferência maciça destas para o colostro no período que antecede o parto (SASAKI et

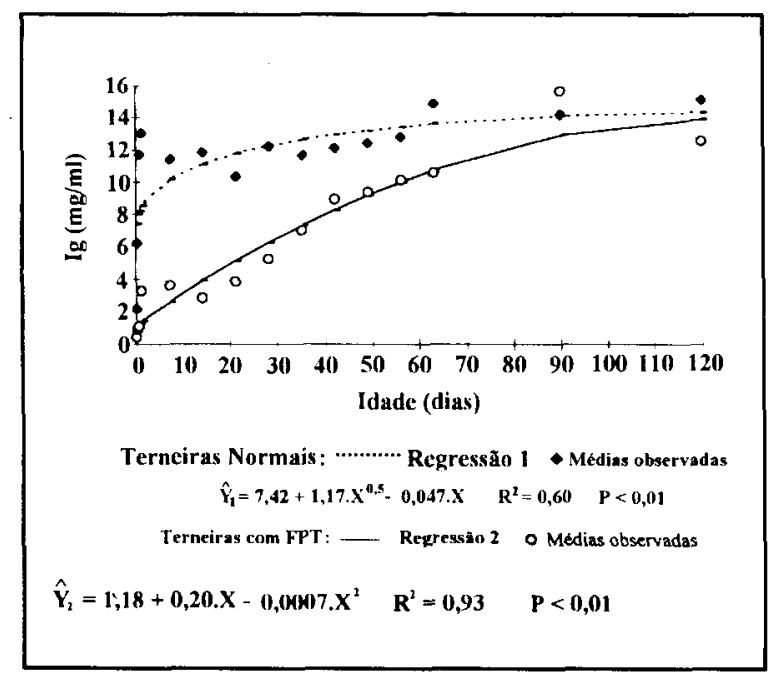

Figura 1 - Evolução das imunoglobulinas séricas médias, medidas pela prova de turvação pelo sulfato de zinco, em terneiras holandesas normais $(n=65)$ e com falha da transferência passiva de anticorpos - FPT $(n=11)$, do nascimento até os 120 dias de idade.

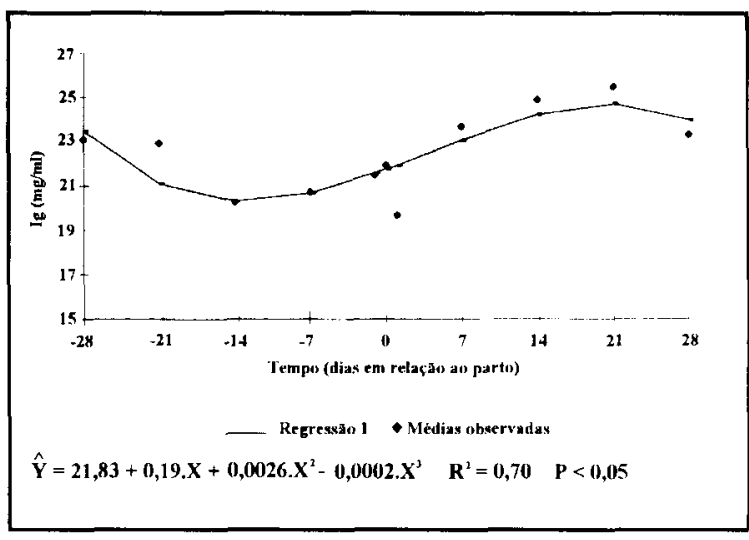

Figura 2 - Evoluçåo de imunoglobulinas séricas médias, medidas pela prova da turvação pelo sulfato de zinco, de 81 vacas holandesas, 28 dias antes do parto até 28 dias após o parto.

al., 1976). BRANDOM et al. (1971) notaram que o nível de Igs alcança máxima concentração na glândula mamária e uma máxima diminuição na circulação sangüinea materna 2 a 3 semanas antes do parto, como constatado no presente estudo. Porém, há relato de que a transferência máxima de imunoglobulinas da corrente sangüínea para a glândula mamária ocorre na semana pré-parto (SASAKI et al., 1976) ou 3 a 10 dias como sugerem WINGER et al. (1995). Essa característica pode interferir na imunidade passiva, pois vacas que sofrem pequeno período seco podem apresentar menores quantidades de Igs em seu colostro (ROY, 1990). Ao pesquisar anticorpos específicos contra BLV, BURRIDGE et al. (1982) detectaram uma queda significativa no título de anticorpos durante o último mês pré-parto em $44 \%$ das fêmeas.

A técnica de turvação pelo sulfato de zinco foi comparada à eletroforese mostrando alta correlação $(r=0,91)$ em 910 soros bovinos. Nesta comparação, não foram utilizadas amostras com concentrações maiores que $40 \mathrm{mg} / \mathrm{ml}$, nem foi possível a realização de eletroforese em amostras de soro com hemólise. A técnica de turvação pelo sulfato de zinco (TSZ) foi descrita por McEWANN (1970) o qual definiu-a como um teste simples e rápido para estimar imunoglobulinas em soros de terneiros. Comparando os dados obtidos pela técnica de turvação pelo sulfato de zinco aos resultados da técnica de imunodifusão quantitativa, esse autor encontrou uma alta correlação $(r=0,96)$ a mesma encontrada por FISHER \& MARTINEZ (1978). RUBIO et al. (1991) utilizando a TSZ e eletroforese em soros de animais adultos e terneiros não encontraram diferenças significativas nos resultados. A utilização de amostras apenas com quantidades 
abaixo de $40 \mathrm{mg} / \mathrm{ml}$ para executar esta comparação baseou-se nas informações de PFEIFFER et al. (1977), que ao comparar quatro técnicas diferentes, encontraram menor somatório dos quadrados médios (MSe) com a TSZ, porém observaram que todas as técnicas possuíam um valor elevado de erro nas amostras acima de 40mg/ml. McEWANN (1970) também encontrou limitações ao relacionar turvação e quantidade de $\gamma$-globulinas em quantidades elevadas. Além disso, não foram utilizadas concentrações maiores que $35 \mathrm{mg} / \mathrm{ml}$ de $\gamma$-globulinas bovina para se calcular a regressão de estimativa. RUBIO et al. (1991) concluíram que utilizando soro diluído $1: 3$ as leituras foram melhores, embora esse procedimento não tenha sido realizado no presente estudo e observou-se que a regressão para estimativa de Igs teve uma correlação semelhante $(r=0,995)$. Esta técnica vem sendo utilizada freqüentemente e demonstra eficiência. Apesar disso, HUDGENS et al. (1996) propõem a utilização de soluções com concentrações maiores de sulfato de zinco com objetivo de melhorar sua especificidade. A técnica mostrou-se prática e precisa na aferição da quantidade de imunoglobulinas séricas, porém tem seu uso restrito, devido a necessidade do uso de equipamento específico. Esta técnica também já foi descrita para avaliação de outras técnicas (PERINO et $\boldsymbol{a l}$., 1993; WHITE, 1986), apresentando-se precisa.

Ao comparar as técnicas de turvação pelo sulfato de zinco e precipitação por sulfito de sódio foram utilizadas 1.467 amostras. Nos intervalos de taxas de imunoglobulinas menores que $5 \mathrm{mg} / \mathrm{ml}$, de 5 a $15 \mathrm{mg} / \mathrm{ml}$ e maiores que $15 \mathrm{mg} / \mathrm{ml}$ encontrou-se eficiência de 62,8\% (91/145), 80,9\% (463/572) e $91,3 \%(688 / 750)$ respectivamente. PFEIFER \& McGUIRE (1977), realizando testes em 21 amostras com seis repetições e utilizando, em casos de dúvidas, a leitura em TSZ como suporte para as leituras, encontraram eficiência de $95,5 \%, 90,0 \%$ e $93,0 \%$. A utilização de amostras com diferentes graus de hemólise também foi realizada não apresentando diferenças.

Ao testar 1.512 amostras de soro bovino pela TSZ e técnica de coagulação por glutaraldeído foi eficiente em 56,7\% (68/120) das amostras com quantidade de imunoglobulinas menores que $4 \mathrm{mg} / \mathrm{ml}$ pela técnica de coagulação pelo glutaraldeído. TENNANT et al. (1979) demonstraram que $100 \%$ das amostras com valores inferiores a $4 \mathrm{mg} / \mathrm{ml}$ foram negativas, porém as concentrações de $\gamma$-globulinas destas amostras variavam de 1 a $2,5 \mathrm{mg} / \mathrm{ml}$. O uso de técnicas qualitativas, portanto, possui um valor limitado na identificação de animais com falha da transferência da imunidade passiva.

\section{CONCLUSÕES}

Os resultados obtidos no presente experimento permitem concluir que:

A concentração de imunoglobulinas séricas em animais com 24 horas de vida apresenta ampla variação. Sendo que os animais com falha da transferência da imunidade passiva apresentam menores níveis de imunoglobulinas até 56 dias de idade.

Vacas prenhes apresentam uma queda da concentração de imunoglobulinas séricas nas duas semanas antes do parto.

A técnica de turvação pelo sulfato de zinco é eficiente para o diagnóstico da falha da transferência da imunidade passiva. Porém, as técnicas de sulfito de sódio e coagulação por glutaraldeído não são precisas para esse fim.

\section{FONTES DE AQUISIÇÃO}

a - ESPECTROFOTÔMETRO E-225D - CELM Companhia Equipadora de Laboratórios Modernos, Barneri. SP

b - DENSITÔMETRO ELETROFORESE Z-30 TURBO - ZÊNITE Indústria e Comércio de Computadores Dedicados LTDA. São Paulo, SP

c - BIOCLIN T.016 - QUIBASA Quimica Básica LTDA, Belo Horizonte, MG.

\section{REFERÊNCIAS BIBLIOGRÁFICAS}

BESSER, T.E., SZENCI, O., GAY, C.C. Decreased colostral immunoglobulins absorption in calves with posnatal respiratory acidosis. J Am Vet Med Assoc, v. 196, n. 8, p. 1239-1243. 1990 .

BRANDOM, M.R., WATSON, D.L., LASCELLES, A.K. The mechanism of transfer of immunoglobulin into mammary secretion of cows. Austr J Biol Med Sci, v. 49, p. 613-623, 1971.

BURRIDGE, M.J., THURMOND, M.C., MLLER, J.M. et al. Falt in antibody titer to bovine leukemia virus in the periparturient period. Can J Comp Med, v.46, p. 270-271, 1982.

DONOVAN, G.A., BADINGA, L., COLLIER, R.J. et al. Factors influencing passive transfer in dairy calves. J Dairy Sci, v. 69 , n. 3, p. 754-759, 1986.

FISHER, E.W., MARTINEZ, A.A. The relationship between the zinc sulfate turbidity test, serum immunoglobulins and the susceptibility of calves to diarrhea. Br Vet J, v. 134, n. 3, p. $231-233,1978$

GARRY, F., ALDRIDGE, B., ADAMS, R. Role of colostral transfer in neonatal calf management: current concepts in diagnosis. Compend Contin Educ, v. 15, n. 8, p. 1167-1174, 1993. 
HANCOCK, D.D. Assessing efficiency of passive immune transfer in dairy herds. J Dairy Sci, v. 68, n. 1, p. 163-183, 1985.

HUDGENS, K.A.R., TYLER, J.W., BESSER, T.E. et al. Optimizing performance of a qualitative zinc sulphate turbidity test for passive transfer of immunoglobulin-G in calves. Am J Vet Res,

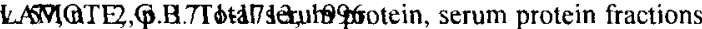
and serum immunoglobulins in colostrum-fed and colostrumdeprived calves. Am J Vet Res, v. 38, n. 2, p. 263-268, 1977

McEWANN, A.D. A turbidity test for the estimation of immune globulin levels in neonatal calf serum. Clin Chim Acta, v. 27, p. $155-163,1970$

MCGUIRE, T.C., PFEIFFER, N.E., WEIKEL, J.M et al. Failure of colostral immunoglobulin transfer in calves dying from infectious disease. J Am Vet Med Assoc, v. 169, n. 7, p. 713$718,1976$.

PERINO, L.J., SUTHERLAND, R.J., WOOLEN, N.E. Determination of passive immunity in calves. Agric Res Service, v. 71, n. 5, p. $176-179,1993$

PERINO, L.J., WITTUM, T.E., ROSS, G.S. Effects of various risk factors on plasma protein and serum immunoglobulin concentrations of calves at post partum hours 10 and 24. Am J Vet Res, v. 56, n. 9, p. 1144-1148, 1995

PFEIFFER, N.E., McGUIRE, T.C. A sodium sulfite-precipitation test for assesment of colostral immunoglobulin transfer to calves. J Am Vet Med Assoc, v. 170, n. 8, p. 809-81 1, 1977.

PFEIFFER, N.E., McGUIRE, T.C., BENDEL, R.B. et al. Quantitation of bovine immunoglobulins: comparison of single radial immunodiffusion, zinc sulfate turbidity, serum electrophoresis, and refractometer methods. Am J Vet Res, v. 38, n. 5, p. $693-$ 698,1977

RAJALA, P., CASTREN, H. Serum immunoglobulin concentrations and health of dairy calves in two management systens from birt to 12 weeks age. J Dairy Sci, v. 78, n. 12, p. 2737 $2744,1995$.

REBELATTO \& WEIBLEN, R. Importância da imunidade passiva para o terneiro. Ciência Rural, v. 22, n. 1, p. 109-118, 1992.

ROBISON, J.D., STOTT, G.H., DENISE, S.K. Effects of passive immunity on growh and survival in the dairy heifer. J Dairy Sci, v. 71, n. 5, p. 1283-1287, 1988.
ROY, J.H.B. The calf - Management of health. 5 ed. London: Butterworths, 1990. Cap. 2: Immunity to disease: p. 17-52

RUBIO, L., ZALDIVAR, V., MAYARI, R. Cuantificación de inmunoglobulinas por turbidez y su aplicación en terneros $y$ bovinos adultos. Rvta Cub Cienc Vet, v. 22, n. 2, p. 113-120, 1991

SASAKI, M., DAVIS, C.L., LARSON, B.L. Production and turnover fo IgG1 and IgG2 immunoglobulins in the bovine around parturition. J Dairy Sci, v. 59, n. 12, p. 2046-2055, 1976

STEEL, R.G.D., TORRIE, J.H. Principles and procedures of statistics. A biometrical approach. 2 ed. New York: McGraw. Hill, 1980.633 p.

STOTT, G.H., WIERSMA, F., MENEFEE, B.E. et al. Influence of environment on passive immunity in calves. J Dairy Sci, v. 59 , n. 7 , p. $1306-1310,1976$.

TENNANT, B., BALDWIN, B.H., BRAUN, R.K et al. Use of glutaraldehyde coagulation test for detection of hipogammag $\left.\right|_{0}$ bulinemia in neonatal calves. $\mathbf{J}$ Am Vet Med Assoc, V. 174, n. 8. p. 848-853, 1979.

TOOD, A.G., WHYTE, P.B.D. The effect of delays on feeding colostrum and the relationship between immunoglobulin concentration in the serum of neonatal calves and their rates of growth. Aust Vet J, v. 72, n. 11, p. 415-417, 1995

WHITE, D.G. Evalaluation of a rapid specific test for detecting colostral IgG1 in the neonatal calf. Vet Rec, v. 119, n. 3, p. $112-114,1986$

WHITE, D.G., ANDREWS, A.H. Adequate concentrations of circulating colostral proteins for market calves. Vet Rec, v. 119 n. 8, p. 112-113, 1986.

WINGER, K., GAY, C.C., BESSER, T.E. Immunoglobulin G transfer into induced mammary secretions: the effect of dexametasone. J Dairy Sci, v. 78, n. 6, p. 1306-1309, 1995

WITTUM, T.E., PERINO, L.J. Passive immune status at post partum hour 24 and long-term health and performance of calves. Am J Vet Res, v. 56, n. 9, p. 1149-1154, 1995.

Ciência Rural, v. 27, n. 3, 1997. 